\title{
Configuring a Better Estimation of Kidney Size in Obese Children and Adolescents
}

\author{
Fahimeh Soheilipour, ${ }^{1, "}$ Fatemeh Jesmi, ${ }^{1}$ Nahid Rahimzadeh, ${ }^{2}$ Mohadeseh Pishgahroudsari, ${ }^{1}$ \\ Fariba Almassinokian, ${ }^{1}$ and Ali Mazaherinezhad ${ }^{1}$ \\ ${ }_{1}^{1}$ Minimally Invasive Surgery Research Center, Iran University of Medical Sciences, Tehran, IR Iran \\ ${ }^{2}$ Department of Pediatric Nephrology, Iran University of Medical Sciences, Tehran, IR Iran \\ ${ }^{*}$ Corresponding author: Fahimeh Soheilipour, Minimally Invasive Surgery Research Center, Iran University of Medical Sciences, Tehran, IR Iran. Tel/Fax: +98-2166555447, E-mail: \\ fsoheilipour@yahoo.com \\ Received 2014 October 28; Accepted 2015 May 8.
}

\begin{abstract}
Background:Obesity ignites numerous health and psychosocial problems and is associated with various comorbidities. Body mass index (BMI) is also independently associated with improved risk for numerous kidney disorders. As renal length is considered a vital parameter in the clinical assessment of renal patients, normal renal length has to be defined in accordance to BMI.

Objectives: The aim of this study was to define normal kidney length in obese children, comparing ultrasound measurements of the kidney length in obese and non-obese children and adolescents, in order to reduce unnecessary evaluations for nephromegaly.

Patients and Methods: Fifty obese children and adolescents and 50 non-obese children and adolescents, aged 1-19 years, were selected from patients of pediatric clinics in two hospitals (Rasoul-e-Akram and Shahid Fahmideh) in Tehran between June 2010 and 2012. After the nephrologist's and endocrinologist's approval, the largest longitudinal renal dimension was measured in deep inspiration position by abdomino-pelvic ultrasonography in both groups.

Results: It was revealed that both kidneys in obese group were significantly larger than in control group $(\mathrm{P}=0.044$ and 0.040 , respectively). Obesity status, height and age were proven to be significant and independent predictors of length of both kidneys. In both groups length of left kidney was significantly larger than that of right kidney $(\mathrm{P}<0.001)$.

Conclusions: A specific standard cut-point limit or norm gram has to be formulated for obese children and adolescents in order to facilitate the diagnosis of kidney diseases, including organomegaly, in these patients.
\end{abstract}

Keywords: Obesity, Children, Adolescents, Kidney, Ultrasonography

\section{Background}

In 2009-2010, the prevalence of obesity in children and adolescents was $16.9 \%$ (1). Obesity in adulthood has its origins mainly in childhood. This makes obesity a pediatric concern for which the necessary therapeutic interventions should be undertaken in this period (2). Currently, the accepted definition of obesity for adults is body mass index(BMI) $\geq 30 \mathrm{~kg} / \mathrm{m}^{2}$ (3). Children are overweight when BMI is greater than 85 th percentile and obese when BMI is greater than $95^{\text {th }}$ percentile $(4,5)$.

Obesity affects around one-fifth of children and adolescents in industrialized countries (6) and is associated with various comorbidities (7), which affect the society's general health tremendously. The high rates of overweight among children and obesity among adults remain a major public health concern (8). Alongside comorbidities like hypertension and diabetes mellitus, which may affect kidney, great BMI is independently as- sociated with proven risk for numerous kidney disorders such as chronic kidney disease, end stage renal disease, renal cell carcinoma and nephrolithiasis (9).

Although kidney length is interconnected to the age of the child (10), the effect of obesity on various organs, including kidney is non-negligible, as children with malnutrition are proven to have less length and volume of the kidney in previous studies (11).

Renal length is considered as a fundamental parameter in clinical assessment of kidney diseases (9) and norm grams specify renal length only for age, therefore we need established norm grams to categorize normal renal length in accordance to BMI in order to reduce unnecessary evaluations for nephromegaly. Moreover, ethnicity plays a great role in determining organ length, and various epidemiologic studies need to be conveyed to detect the normal organ length in each community.

Copyright (C) 2016, Growth \& Development Research Center. This is an open-access article distributed under the terms of the Creative Commons Attribution-NonCommercial 4.0 International License (http://creativecommons.org/licenses/by-nc/4.0/) which permits copy and redistribute the material just in noncommercial usages, provided the original work is properly cited. 


\section{Objectives}

Therefore, we designed this cross-sectional cohort study in an Iranian sample to ignite the idea to form norm grams of kidney length related to BMI.

\section{Patients and Methods}

\subsection{Patient Selection}

hundred children and adolescents, aged 1 - 19 years, referred to the pediatric clinics of three hospitals (Rasoule-Akram and Shahid Fahmideh) in Tehran between June 2010 and 2012, were enrolled into the study after the nephrologist's and endocrinologist's approval. Fifty obese children and adolescents were selected as the case group, who were matched by age and gender to 50 non-obese children and adolescents as the control group. Participants were allocated according to the 2000 CDC growth charts (5); normal weight was defined as BMI $=5-85^{\text {th }}$, and overweight/obese as BMI $\geq 95^{\text {th }}$ percentile. Participants between $85^{\text {th }}$ and $95^{\text {th }}$ percentiles were not enrolled in the study. Any patient with abnormal blood pressure, family or personal history of any urinary diseases, obesity due to any systemic disease was excluded from the study. All participants underwent abdominal-pelvic ultrasonography, which was done by a single specialist, using a $3.5 \mathrm{MHz}$ sector probe with an accuracy of $0.1 \mathrm{~mm}$. Each kidney was measured separately and the largest longitudinal dimension was measured in deep inspiration. Any patient with abnormal renal appearance on ultrasound was excluded from the study. Data were collected for each patient including age, gender, height, BMI and body surface area (BSA). The protocol of the survey has been proven by the ethic committee of Iran University of Medical Sciences, Tehran, by the code 89-04-140-12348.

\subsection{Statistical Methods}

Statistical analysis was performed by SPSS 11.5 for windows. Analysis of the data distribution was assessed by the Kolmogorove-Smirnove test. Mean and standard deviations or median with interquartile range were calculated for quantitative data and frequency with percent for qualitative data. For determining the relationship between kidney length and all independent variables, the Pearson coefficient of correlation was used. Predictor factors for kidney length were determined by a forward multiple linear regression analysis for the right and left kidney differences. The kidney length between groups was compared by Independent-samples t-test or its non-parametric test, MannWhitney test; paired-sample t test was used to compare left and right kidney length within the groups. Less than 0.05 was accepted as indicating statistical significance.

\section{Results}

We included 50 obese children and adolescents (case group) and 50 normal weights (control group). The mean age of case group was $134.62 \pm 47.97$ (range $45-210$, median 138 ) months and of the control group (range $30-207$, median 136.5) months. The case group had similar mean age $(P=0.838)$, gender $(P=0.547)$ and age group $(P=0.807)$ to controls, but as expected higher weight, BMI and BSA than that of control group ( $\mathrm{P}<0.001$ for all) (Table 1$)$. There was no significant difference of mean height in groups after we had adjusted it for age $(P>0.05)$. There was no significant difference between male and female case group in age, weight, height, BMI, BSA ( $P>0.05$ ) (Data are not shown). Clinical characteristics of both groups are shown in Table 1. Paired Student's t-test demonstrated that length of the left kidney was significantly larger than that of the right kidney in obese and control groups ( $\mathrm{P}<0.001$ for both groups; Table 2$)$.

\begin{tabular}{|c|c|c|c|}
\hline Variable & Control Group ${ }^{\mathbf{b}}$ & Obese Group ${ }^{\mathbf{b}}$ & P Value \\
\hline Gender & & & 0.547 \\
\hline Male & $27(54)$ & $24(48)$ & \\
\hline Female & $23(46)$ & $26(52)$ & \\
\hline Age, mon & $132.62 \pm 49.40$ & $134.62 \pm 47.97$ & 0.838 \\
\hline Height, cm & $144.44 \pm 23.0$ & $145.94 \pm 22.05$ & 0.744 \\
\hline Weight, kg & $39.20 \pm 15.96$ & $67.02 \pm 24.83$ & \\
\hline BMI, $\mathrm{Kg} / \mathrm{m}^{2}$ & $17.74 \pm 2.21$ & $29.54 \pm 5.14$ & \\
\hline Z Score of BMI & $0.10 \pm 0.53$ & $2.37 \pm 0.44$ & \\
\hline BSA & $1.23 \pm 0.36$ & $1.63 \pm 0.43$ & \\
\hline Age categories & & & 0.807 \\
\hline $1-72$, mon & $7(14)$ & $5(10)$ & \\
\hline $6-12, y$ & $20(40)$ & $22(44)$ & \\
\hline $12-19, \mathrm{y}$ & $23(46)$ & $23(46)$ & \\
\hline
\end{tabular}

a Data are expressed as No. (\%) or mean \pm SD.

$\mathrm{b}_{\mathrm{N}=50 \text {. }}$ 
Also analysis revealed that left and right kidney length in obese group was significantly higher than in control group ( $\mathrm{P}=0.044$ and 0.040 , respectively); after dividing two groups into three age ranges, the same result was found for 6,12,14 year and also 12-19 year ranges (Table 2); the difference of kidney length between the two groups was still found significant while controlling the effect of age, height and sex $(\mathrm{P}<0.001)$. We found significant gender-related difference in right kidney length in neither the control ( $86.26 \pm 13.20$, male vs. $86.17 \pm 11.85$, female; $\mathrm{P}=0.981)$ nor obese (90.92 \pm 10.86 , male vs. $91.58 \pm 13.52$, female; $\mathrm{P}=0.851)$, the same result was found for the left kidney length, in the control (89.26 \pm 13.78 , male vs. 86.96 \pm 13.04 , female; $\mathrm{P}=0.549$ ) and the obese group (94.33 \pm 10.98, male vs. $92.92 \pm 13.94$, female; $\mathrm{P}=0.695$ ).

Analyzing data yielded a significant linear association between right and left kidney length with each other and with age, height, weight, BMI and BSA ( $\mathrm{P}<0.0001$ for all) in control and obese group (Table 3 ). In the obese group, the correlation coefficients for right kidney length with all these independent variables were similar to that for the left kidney length; a similar result was found for the control group; as shown in Table 3, all these coefficients for the control group are higher than those in obese group.
Linear regression equations for the length of kidneys and independent predictors such as obesity status, age and height are shown in Table 4 . These variables have a significant positive relationship with the length of kidneys; on the other hand, with increasing height (right kidney length: $\beta=0.245$; left kidney length: $\beta=0.177$ ) and age (right kidney length: $\beta=0.119$; left kidney length: $\beta=$ $0.165)$, the average length of kidneys increases. Also according to the $\beta$ coefficient for the obesity status in the equations for right $(\beta=4.440 \mathrm{~mm})$ and left $(\beta=4.805$ $\mathrm{mm}$ ), kidney lengths for the obese children and adolescents were significantly higher than those for the normal weight group with the same age and height (adjusted for age and height). When age was removed from the model, obesity status and height still remained significant predictors of kidney length $(\mathrm{P}<0.001$; Table 4$)$.

Linear regression equations for right and left kidney lengths and height were then created for both groups (Figures 1 and 2). The scatter plots illustrate that the height is linearly related to length of both kidneys in obese and control groups. The equations for the obese and control groups were found to parallel each other and were also significantly different from each other for both right and left kidneys $(\mathrm{P}<0.01)$.

\begin{tabular}{|c|c|c|c|}
\hline Age Ranges Groups & Control Group $^{\text {b }}$ & Obese Group ${ }^{\text {b }}$ & P Value \\
\hline \multicolumn{4}{|l|}{ 1-72 Months, mm } \\
\hline Left kidney length & $66.14 \pm 10.94$ & $68.80 \pm 8.79$ & 0.664 \\
\hline Right kidney length & $64.86 \pm 10.06$ & $66.00 \pm 7.71$ & 0.836 \\
\hline \multicolumn{4}{|l|}{ 6-12 Years, mm } \\
\hline Left kidney length & $83.80 \pm 4.59$ & $88.45(85.00-94.25)$ & 0.004 \\
\hline Right kidney length & $82.85 \pm 4.50$ & $86.73(85.75-91.25)$ & 0.003 \\
\hline \multicolumn{4}{|l|}{ 12-19 Years, mm } \\
\hline Left kidney length & $99.61 \pm 6.15$ & $100.50(98.00-100.80)$ & 0.019 \\
\hline Right kidney length & $96.52 \pm 5.78$ & $100.65 \pm 4.99$ & 0.013 \\
\hline \multicolumn{4}{|l|}{ All ages range, $\mathrm{mm}$} \\
\hline Left kidney length & $88.20 \pm 13.36$ & $93.60 \pm 12.50$ & 0.040 \\
\hline Right kidney length & $86.22 \pm 12.47$ & $91.26 \pm 12.20$ & 0.044 \\
\hline
\end{tabular}

a Data are expressed as No. (\%) or mean \pm SD.

$\mathrm{b}_{\mathrm{N}}=50$.

Table 3. Multiple Linear Regression Equation of of Obese and Control Groups For Right and Left Kidneys ${ }^{\mathrm{a}}$

\begin{tabular}{lccc}
\hline Predictor Model & Equation ${ }^{\mathbf{b}}$ & $\mathbf{R}^{\mathbf{2}}$ & P Value \\
\hline Right Kidney length & & & $<0.001$ \\
\hline Obesity statues, height, age & $35.170+4.440 \mathrm{x}+0.245 \mathrm{y}+0.119 \mathrm{z}$ & 0.835 & $<0.001$ \\
$\quad$ Obesity status, height & $15.863+4.309 \mathrm{x}+0.487 \mathrm{y}$ & 0.820 & \\
Left Kidney length & & & \\
Obesity statues, height, age & $40.773+4.805 \mathrm{x}+0.177 \mathrm{y}+0.165 \mathrm{z}$ & 0.832 & 0.859 \\
\hline Obesity statues, height & $13.858+4.628 \mathrm{x}+0.515 \mathrm{y}$ & & \\
\hline
\end{tabular}

a Predictors: Obesity statues, height, age; Dependent variables: Right and left Kidney length.

$\mathrm{b}_{\mathrm{x}}=$ Obesity statues: $0=$ Control; $1=$ Obese; $\mathrm{y}=$ Height; $\mathrm{z}=$ Age. 
Soheilipour F et al.

\begin{tabular}{|c|c|c|c|c|c|c|}
\hline Parameter & Age, mon & Height, cm & Weight, Kg & BMI, $\mathrm{kg} / \mathrm{m}^{2}$ & BSA, $\mathrm{cm}^{2}$ & Left Kidney \\
\hline Control group $\mathbf{b}$ & & & & & & 0.971 \\
\hline Left kidney length & 0.949 & 0.935 & 0.914 & 0.815 & 0.938 & \\
\hline Right kidney length & 0.931 & 0.924 & 0.895 & 0.796 & 0.923 & \\
\hline Obese group $\mathbf{b}$ & & & & & & 0.941 \\
\hline Left kidney length & 0.893 & 0.881 & 0.864 & 0.564 & 0.882 & \\
\hline Right kidney length & 0.876 & 0.882 & 0.876 & 0.634 & 0.891 & \\
\hline
\end{tabular}

${ }^{\mathrm{a}}$ Correlation is significant at the 0.001 level (2-tailed); data are given as the Pearson Correlation Coefficient.

$\mathrm{b}_{\mathrm{N}=50 \text {. }}$

A

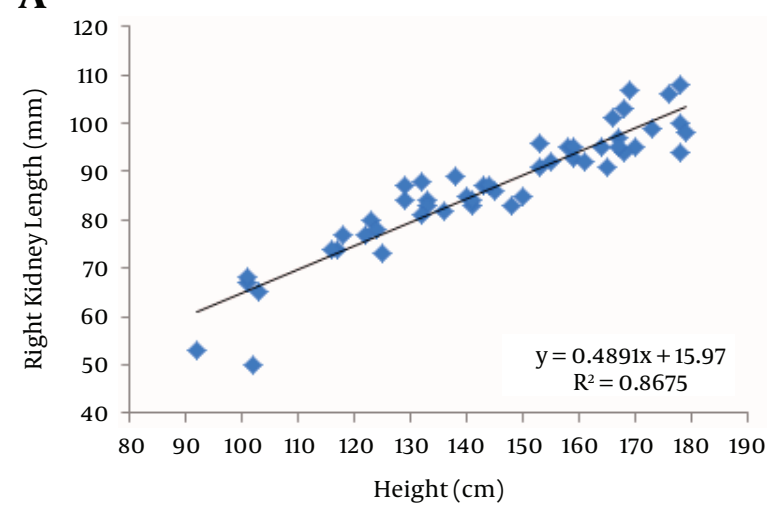

B

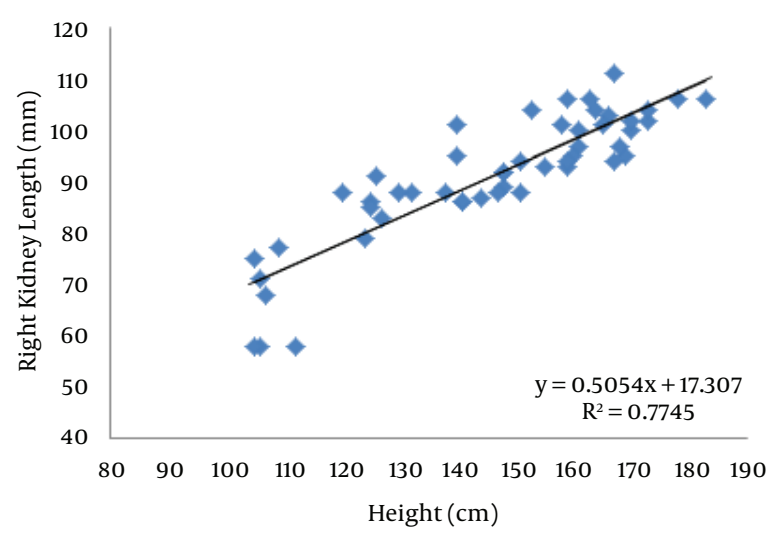

Figure 1. Kidney length norm gram based on height for (A) control group and (B) obese group for the right kidney length.

\section{Discussion}

Our results showed that left and right kidney length in obese group was significantly higher than in control group, the same result was found in 6-12 year and also 12-19 year ranges and it was not seen for first range (172 month range); that is because the sample size in 1-72 month group is too small to show such a difference. Our study demonstrated that in both groups the kidney length increases with age, height and BMI, and also linear

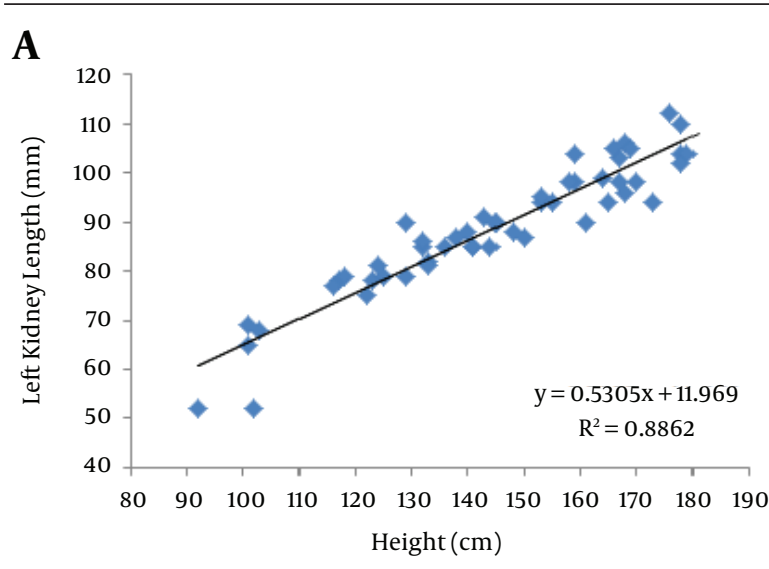

B

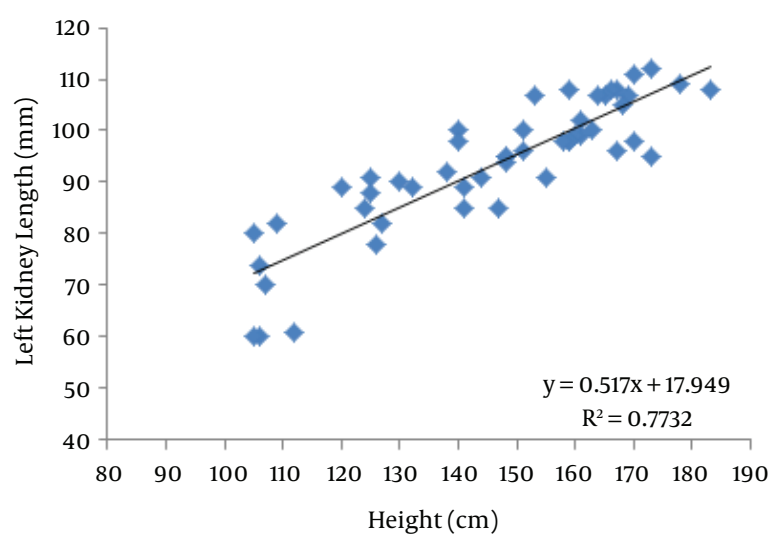

Figure 2. Kidney Length norm gram based on height for (A) control group and (B) obese group for the right kidney length.

regression equations formulated for right and left kidney may help physicians reconsider the cut-off level of kidney size for obese patients to inhibit the flaw of investigating these children and adolescents for organomegaly.

Many studies have investigated the direct and indirect effects of obesity on kidney diseases, such as end stage renal disease and chronic kidney disease $(6,10,11)$ and some other have justified that solving obesity will solve these 
diseases (11). Others have concluded that malnutrition is also associated with lower kidney size (12). Yet, these studies have the confounding factor of including patients with co-morbidities and therefore cannot evaluate the pure effect of obesity on kidney size.

In the current study we excluded all children and adolescents with any kidney abnormality in order to assess the pure effect of obesity on the kidney length and have included children and adolescents of all ages. Some studies have studied children under two years; Akhavan et al. have proposed an age-based formula for predicting renal length in children aged 0-18 months (9). Schmidt et al. have also reported variations according to age, height and body composition of 717 healthy children of 0-18 months (13). Geelhoed et al. have also reported some variations associated with infantile and maternal factors (14). These studies mostly emphasize the characteristic changes of kidney volume in children and adolescents younger than two years and therefore cannot be generalized to all children.

These studies have associated larger kidney size in males to sex steroid and growth hormone in addition to body composition. Our study considered children and adolescents of all ages and found no significant difference in kidney length regarding gender neither in case nor in control group. Some studies have assessed kidney weight in autopsies, which was best predicted by body surface area and was lower in obese (15). Zuzuarregui et al. have conducted a retrospective study on 204 healthy children in 2009 and proposed a linear norm gram for kidney size based on height, using ultrasonography, and have reported that healthy obese children have enlarged kidneys with no abnormality, but have declared some complications in norm gram, as they have included pure hematuria (16). Yet we have divided the participants into two groups regarding their BMI in order to be able to assess the pure effect of obesity on kidney length and have excluded all abnormalities, even pure hematuria, in order to be able to assess healthy kidneys. On the other hand, each society might have different values, regarding ethnicity, race and etc. discrepancies.

Parallel to the Zuzuarregui's study, we have also found no gender-related difference in kidney length. The height of the obese group has been proposed to be larger in some studies (16), but we did not find any difference in height of the two groups.

These results urge a re-consideration before marking the obese child with nephromegaly, in order to prevent unnecessary clinical assessments and save patient and physician's time, money and energy.

Further studies might imply that the definition of organomelies ought to change in obese children and adolescents and norm grams, e.g. CDC norm grams, need to be validated for assessing organ lengths according to the effective predictors, such as age, height and BMI. Our study had some limitations. First, we only measured the kidney length by ultrasound, but the kidney volume might be more appropriate for a better assessment of kid- ney. Second, this study could be done with a larger sample size to reduce the probable bias occurring, although we have seen positive effect with this sample size too. Considering the difference in kidney size of obese children and adolescents compared to leans and the growing prevalence of obesity in our society, it is worthwhile to conduct a large cohort study on all societies to formulate a specific standard cut-point limit or norm gram for obese children and adolescents, in order to facilitate the diagnosis of kidney diseases, including organomegaly, in obese children and adolescents.

In conclusion we can say that in all age groups of children and adolescents, there is a significant difference in kidney length between normal weight and obese participants and interpretation of nephromegaly for obese children and adolescents can lead to some unnecessary workups, when decided according to age-specified charts, which have not taken BMI into account.

\section{Acknowledgments}

We would like to thank Prof. Zarrabi and all the dear ones who have helped us in performing this survey.

\section{References}

1. Ogden CL, Carroll MD, Kit BK, Flegal KM. Prevalence of obesity and trends in body mass index among US children and adolescents, 1999-2010. JAMA. 2012;307(5):483-90. doi: 10.1001/jama.2012.40. [PubMed: 22253364]

2. Lifshitz F. Obesity in children. J Clin Res Pediatr Endocrinol. 2008;1(2):53-60. doi: 10.4008/jcrpe.v1i2.35. [PubMed: 21318065]

3. Pietrobelli A, Faith MS, Allison DB, Gallagher D, Chiumello G Heymsfield SB. Body mass index as a measure of adiposity among children and adolescents: a validation study. J Pediatr. 1998;132(2):204-10. [PubMed: 9506629]

4. Kuczmarski RJ, Ogden CL, Guo SS, Grummer-Strawn LM, Flegal KM, Mei Z, et al. 2000 CDC Growth Charts for the United States: methods and development. Vital Health Stat 11. 2002;(246):1-190. [PubMed:12043359]

5. Body Mass Index (BMI) [updated May 15, 2015]; [cited 14 Feb];Division of Nutrition, Physical Activity, and Obesity. 2014

6. Wang Y, Chen X, Klag MI, Caballero B. Epidemic of childhood obesity: implications for kidney disease. Adv Chronic Kidney Dis. 2006;13(4):336-51. doi: 10.1053/j.ackd.2006.07.016. [PubMed: 17045220]

7. Puder JJ, Munsch S. Psychological correlates of childhood obesity. Int J Obes (Lond). 2010;34 Suppl 2:S37-43. doi:10.1038/ijo.2010.238. [PubMed: 21151145]

8. Hedley AA, Ogden CL, Johnson CL, Carroll MD, Curtin LR, Flegal KM. Prevalence of overweight and obesity among US children, adolescents, and adults, 1999-2002. JAMA. 2004;291(23):2847-50. doi:10.1001/jama.291.23.2847. [PubMed:15199035]

9. Akhavan A, Brajtbord JS, McLeod DJ, Kabarriti AE, Rosenberg HK, Stock JA. Simple, age-based formula for predicting renal length in children. Urology. 2011;78(2):405-10. doi: 10.1016/j.urology.2011.01.008. [PubMed: 21459422]

10. Srivastava T. Nondiabetic consequences of obesity on kidney. Pe diatr Nephrol. 2006;21(4):463-70. doi: 10.1007/s00467-006-00274. [PubMed: 16491417$]$

11. Alicic RZ, Patakoti R, Tuttle KR. Direct and indirect effects of obesity on the kidney. Adv Chronic Kidney Dis. 2013;20(2):121-7. doi: 10.1053/j.ackd.2012.12.006. [PubMed:23439370]

12. Ece A, Gozu A, Bukte Y, Tutanc M, Kocamaz H. The effect of malnutrition on kidney size in children. Pediatr Nephrol.2007;22(6):85763. doi: 10.1007/s00 467-006-0338-5. [PubMed: 17053884]

13. Schmidt IM, Main KM, Damgaard IN, Mau C, Haavisto AM, Chel- 
lakooty M, et al. Kidney growth in 717 healthy children aged 0-18 months: a longitudinal cohort study. Pediatr Nephrol. 2004;19(9):992-1003. doi: 10.1007/s00467-004-1479-z. [PubMed: 15206038]

14. Geelhoed JJ, Verburg BO, Nauta J, Lequin M, Hofman A, Moll HA, et al. Tracking and determinants of kidney size from fetal life until the age of 2 years: the Generation R Study. Am J Kidney Dis. 2009;53(2):248-58. doi: 10.1053/j.ajkd.2008.07.030. [PubMed:
18848377]

15. Haddad-Zebouni S, Hindy R, Slaba S, Aoun N, Mourani C. Evaluation echographique de la taille des reins, du foie et de la rate chez l'enfant. Arch de Pediatr. 1999;6(12):1266-70. doi: 10.1016| s0929-693x(00)88887-9.

16. Zuzuarregui J, Mallios R, Murphy J. The effect of obesity on kidney length in a healthy pediatric population. Pedic Nephrol. 2009;24(10):2023-7. 